\title{
PROMOTING SUSTAINABLE DEVELOPMENT THROUGH FISHERIES-RELATED TOURISM EXPERIENCES. BENEFITS FROM THE INTEGRATION BETWEEN FISHERIES AND TOURISM IN VENETIAN COASTAL AREAS
}

\author{
S. MENEGHELLO \& E. MINGOTTO \\ CISET - International Centre of Studies on Tourism Economics, Ca' Foscari University of Venice, Italy.
}

\begin{abstract}
Fisheries-related tourism is developing in several European coastal regions as a product that, by linking fisheries to tourism, can be an answer both to the need to develop innovative tourism products and to the priority to find new sources of income for profitable and more sustainable fisheries. The paper discusses the main findings of a research project carried out by the authors about the potentials of pescatourism along Venetian coasts in Italy. It focusses on the opportunities coming from pesca-tourism in terms of additional income for fishermen, economic benefits on the destination due to new tourists' spending, improvement in the quality of life and awareness about ecosystems' fragility and sustainable development. In particular, the paper shows pesca-tourism potential for the area in the medium-long term, provided that a win-win cooperation is established among local stakeholders, tourism operators and fishermen. According to the findings, fisheries-related tourism represents a way of differentiating tourism products, by promoting a broader territorial experience with a positive economic return on various public and private players, together with a more sustainable approach towards tourism and fisheries development.

Keywords: coastal tourism, fisheries, fisheries-related tourism, ichtitourism, pesca-tourism, sustainable development.
\end{abstract}

\section{INTRODUCTION}

Fisheries-related tourism is becoming a more and more interesting way to support the fishing sector, particularly by providing a valuable opportunity for fishermen to complement their incomes and developing a more sustainable sector's grow [1,2]. Moreover, fisheries-related tourism represents a new tourist proposal both for coastal tourism destinations where innovation and differentiation strategies are necessary to preserve consolidated competitive advantages and for hinterland destinations where tourism development focusses on local communities, activities and production as attractions [2].

Over the last years the European Commission has strongly promoted the development of projects in coastal and maritime areas focused on the diversification of fishing activities and their integration with the tourism sector [3-8]. The European Fisheries Fund (EFF) highlighted the importance of sustainable development and improvement of the quality of life in fisheries areas describing the Priority Axis 4 in the Council Regulation EC N. 1198/2006 [9].

Main expressions of fisheries-related tourism are pesca-tourism and ichthytourism. Different national legislative acts $[6,10]$ agree in defining pesca-tourism as a set of recreational

This paper is part of the Proceedings of the $7^{\text {th }}$ International Conference on Sustainable Tourism (Sustainable Tourism 2016)

www.witconferences.com 
activities based on boarding non-crew individuals on fishing vessels. Only professional fishermen can propose pesca-tourism activities, usually according to territorial specificities of the context in which they operate. A variety of destinations can be reached along the coastline, on/around the islands, along rivers, lagoons and deep sea fishing areas. Pesca-tourism activities include:

- boat excursions, watching and participating in fishing activities;

- introduction to fishing methods, observation of professional fishing techniques and learning how to catch fish;

- preparation of lunch/dinner on board;

- providing information on the marine environment and coastal biodiversity of local areas.

Whereas pesca-tourism can be considered still in its childhood stage across the Mediterranean level, ichthytourism can even be thought in the infancy stage. Indeed, for this specific sector, the legislative and operational framework is not exhaustively defined even by local authorities. Ichthytourism is a variety of fisheries-related activities including recreational, educational, culinary and hospitality services [10]. The main difference between pesca-tourism and ichthytourism is that ichthytourism activities are organised mainly on the mainland, where infrastructures traditionally devoted to fishing - docks, fishing huts, suspended fishing nets, fishnet shelters - are located.

In Italy, for example, pesca-tourism and ichthytourism are defined by National Legislative Decree D.Lgs. n, 154 of 26 May 2004, art. 7 [10] and by other specific national laws. It is mandatory for the fisherman to receive formal authorization to practice recreational activities by the Head of the maritime compartment where the fishing vessel is registered (Harbour Authority), moreover vessels should be equipped and registered for fishing with all the necessary safety and hygiene equipment. Furthermore it is mandatory that fishing activities have a priority role on fisheries-related tourism activities. Apart from common national regulations, each single region defines fisheries-related tourism by a specific independent regional legislation mainly in compliance with the national law. In some regions debates for the development of specific regulations are currently ongoing, other regions have already legislated but activities are not particularly well developed since recommendations drawn by fishermen and experts have not been taken into account and open questions are still there (for example on safety and hygiene issues).

From the point of view of the tourism sector, fisheries-related tourism can be perfectly integrated with niche tourism products defining several coastal and maritime destinations such as nature-based tourism and ecotourism, food tourism, cultural landscape tourism. Fisheries-related tourism can add value to these experiences promoting local fish food and communities, slow mobility and awareness about the fragility of environmental contexts [2].

\section{THE ITALIAN AND EUROPEAN FRAMEWORK}

Even if the sector has shown an interesting development in comparison to fifteen years ago or so, a map of different European and Italian experiences confirms that fisheries-related tourism is still a pioneering tourism product.

Nowadays fishing enterprises or cooperatives proposing pesca-tourism and/or ichthytourism can be found in some relevant maritime areas. Most of these experiences are interesting cases because their promoters usually go beyond individual business profit and are interested in creating relations with local stakeholders by organising and coordinating an integrated tourism offer of fisheries-related tourism with other local attractions. 
Some of these virtuous entities are also active members of FARNET, the Fisheries European Area Network working on projects financed by the European Commission under EFF (European Fisheries Fund) in years 2007-2013, and under EMFF (European Maritime and Fisheries Fund) throughout the period 2014-2020. FARNET is the community of people implementing different Community-Led Local Development (CLLD) bringing together Fisheries Local Action Groups (FLAGs). FLAGs are local partnerships among the private sector, local authorities, citizens and experts within the framework of a strategy, developed in response to specific needs and opportunities identified locally. In October 2013 the Farnet Network organised the seminar 'Linking Fisheries to the Tourism Economy' focusing on the opportunities deriving from the relationship between Fisheries and Tourism. More than 80 FLAGs from 20 European countries together with tourism industry experts took part in the seminar concentrating on key themes like matching fisheries areas' assets with potential markets, developing tourism products linked to fisheries, and marketing and sales of fisheries-related tourism [11]. Analyses of the documents produced by the European Farnet Network together with online desk analyses and focus groups realized with Italian fishing enterprises and experts allowed to map European and Italian effective fisheries-related tourism experiences. The following mapping is not claiming to be comprehensive but can be considered as a starting point to understand the level of development of the sector and the territorial distribution of positive experiences.

Here the description of some relevant European cases.

- The Mar Galaica project carried out in Galicia (Spain) represents an example of developing quality fisheries-related products which started with one FLAG territory (Fisterra) and then included all Galician FLAGs and possibly to be extended to other Spanish regions. In its first year about 60 enterprises got involved and about 150 people attended classes to improve their tourism competences. They became members of the MarGalaica Club and signed the quality card 'Fisterra Standard'. As a result in two years more than 250 tourism packages among the 97 fisheries-related tourism products have been sold [7].

- In Sodankyla, a small city in Lapland-Finland, between 2009 and 2011 a tailor made training programme for fishermen has been developed. Fishermen from Northern and Western Lapland took the opportunity to improve their skills to guarantee adequate quality standards of tourist services. Local fishermen took part in study visits at tourism enterprises, building relationships, learning about packaging tourism products, price definition, distribution channels and promotion strategies [8].

- The French project Pescatourisme 83 is noteworthy because of the encouragement of the legislative evolution necessary to facilitate fisheries-related activities around the French coast. Moreover, the project fostered the creation of a national working group on pescatourism within the Ministry's Department of Fishing and Aquaculture including accurate work on safety and fiscal legislation [6].

Here the description of some relevant Italian cases [12].

- In Orbetello, a coastal destination of the Tuscany province of Grosseto, the integration between tourism and traditional activities of fisheries has been consolidating for fifteen years and more. The Orbetello Pesca Lagunare, the most active subject of the project, preserves old fisheries tradition. The project includes ichthytourism where tasting and purchasing of lagoon produce and excursions on boat are possible. 
- The Egadi islands in Sicily represent another example of tourism destination focusing on the differentiation of its tourism offer. Here the San Giuseppe cooperative, pioneer in the launch of pesca-tourism and ichthytourism in Italy back in 1995, has been promoting over the past years a project in response to the economic crises of the sector providing a valuable opportunity for fishermen to complement their incomes.

- The eastern Sardinia Flag was born in 2010 to develop projects for the socio-economic development of this coastal area. The Local Development Plan, titled 'Eastern Sardinia towards 2020', focusses on 13 actions mainly aimed at promoting fishing activities, sustainable management of water resources, and the strengthening of pesca-tourism and ichthytourism as economic differentiating activities.

- The venetian case will be examined in depth in the following paragraph.

All European and Italian successful cases stress some key-issues such as the need to integrate different local resources and traditions and to involve fishermen, their families and the hosting community, as well as the length of time needed for a new tourism product to be recognized from the potential demand, moreover the difficulty for fishermen to learn the appropriate skills. All the success cases here illustrated sprouted from the increasing marginalisation of the fisheries sector from the rest of the local community and the urgency to re-engage with the general public. These factors have been the key to push the development of remarkable fisheries-related tourism experiences in these coastal areas.

\section{THE VENETIAN COAST CASE STUDY}

\subsection{The area under consideration}

Talking about fisheries-related tourism, a crucial question is to define its potentials in favour of both fishermen and tourism operators and the overall destination. This paragraph then discusses the main findings of a study carried out by the authors about the opportunity to develop fisheries-related tourism along Venetian coasts in Italy.

The area under consideration is a $60 \mathrm{Km}$ coastline close to Venice and its lagoon; it is one of the most important and well known tourism destinations in Italy, thanks to its proximity to long-established, popular seaside resorts and to Venice. In fact, the Venetian coast is included in the so-called 'Venetian tourism region', since it is popular among tourists who are attracted by the city of Venice but who prefer to stay in locations near Venice because of less expensive accommodation, special interests, accessibility. The overall coastal area accounts on average for 3 millions tourist arrivals and 22 millions overnight stays, with a significant supremacy of the international market in comparison to the domestic demand. The importance of this area is evident: it represents $20 \%$ of arrivals and $35 \%$ of overnights registered in the whole Veneto Region.

The Venetian coastline is relevant for fisheries too: 400 local companies and 470 employees are active in this sector with a fishing fleet of 320 vessels. The two largest fish markets in the area distribute more than 32,000 tonnes of fish, in other words the $30 \%$ of the overall fish production marketed in the Veneto Region.

The Venetian coast is located in the North Adriatic Sea, the most abundant and productive sea in Italy, being particularly suitable as a 'nursery' for fish to grow and develop thanks to the perfect thermal and tropic conditions. Since the catching or destruction of this precious 
fish stock can cause the impoverishment of the fish population, sustainable development in the fisheries sector is extremely necessary along Venetian coasts.

Moreover, the overall area, that has a strong connection to water since it is characterised by lagoons - Venice and its lagoon are included in the UNESCO World Heritage List - fish farms, natural and artificial waterways, is made of fascinating but fragile ecosystems. Sustainable development is then imperative for all economic and recreational activities developed in the area.

\subsection{The estimation of the potential demand}

A first relevant element for understanding the real potentials of fisheries-related tourism development along Venetian coasts is the size of the potential demand, i.e. how many potential visitors could be interested in pesca-tourism and/or ichthytourism experiences. This demand can be generated both by residents - local people living along the costline and in neighbouring areas - and by tourists who are on holiday in the seaside resorts and neighbouring destinations.

The authors have then estimated the potential demand taking into account the catchment area and then applying a percentage corresponding to residents' and tourists' willingness to experience pesca-tourism and/or ichthytourism. While the size of the catchment area is derived from official statistics available in the National and Regional Statistics Office, information about the willingness come from previous studies and surveys carried out by the authors and other bodies among visitors in the area under consideration [13-16].

The main steps that lead from the catchment area to the potential demand estimation are summarised below.

1. The catchment area includes both residents and tourists living or staying along the Venetian coast or in locations that are no longer than 2 hours away from the coastline. Indeed, a distance of more than two hours prevents both residents and tourists from organising same-day excursions. The catchment area then accounts for 2.6 millions residents and 3.6 millions tourists.

2. A first information about consumers'attitudes is the willingness to carry out excursions related to the discovery of naturalistic areas, traditions and local people in their free time. It corresponds to $30 \%$ for residents and to 5\%-10\% for tourists according to the holiday motivation and to the location in which they stay. Applying these percentages, potential visitors who can show an interest also in fisheries-related tourism are about 1 million people (800,000 residents and 225,000 tourists).

3. The third step aims at finalising the estimation obtaining a more realistic evaluation, by considering in particular the attitude to live experiences concerning specifically fisheriesrelated tourism such as excursions on board fishing boats, visits to traditional fishermen huts, tastings of local fish dishes, etc. While residents' willingness is about $12 \%$, tourists' willingness is about $1 \%-7 \%$. Applying these percentages to the preliminary estimation of natural resources' estimators, the potential demand accounts for almost 110,000 people (94,000 residents and 14,000 tourists). Therefore this value represents the number of visitors that Venetian fishermen can potentially attract and that they can consider for strategic decisions. 
Table 1: Potential demand.

\begin{tabular}{llll}
\hline & Residents & \multicolumn{1}{c}{ Tourists } & Total demand \\
\hline $\begin{array}{l}\text { Catchment area } \\
\begin{array}{l}\text { Visitors interested in doing excursions } \\
\text { related to the discovery of naturalistic }\end{array}\end{array}$ & $2,600,000$ & $3,600,000$ & $6,200,000$ \\
$\begin{array}{l}\text { areas, traditions and local people } \\
\text { during their spare time }\end{array}$ & 225,000 & $1,025,000$ \\
$\begin{array}{l}\text { Visitors interested in doing } \\
\text { experiences related to fisheries- } \\
\text { related tourism during their spare } \\
\text { time }\end{array}$ & $\mathbf{9 4 , 0 0 0}$ & $\mathbf{1 4 , 0 0 0}$ & $\mathbf{1 0 8 , 0 0 0}$ \\
\hline
\end{tabular}

\subsection{Three scenarios for fishermen's turnover}

Since fisheries-related tourism should represent an additional source of income for fishermen, it is important to assess the benefits that these activities can bring to them. In particular, it is useful to verify whether it is profitable to practice fisheries-related tourism in addition to the traditional fishing activities and if the potential demand is broad enough to ensure satisfactory results for all.

At this point it must be pointed that along Venetian coasts fisheries-related tourism supply is still in its early days, since fishermen do not practice pesca-tourism or ichthytourism yet. However there are almost 90 fishermen that have already attended the training course required by the regional law to obtain the necessary licence to start the business. These fishermen are then the operators who right now are convinced to differentiate their activities in the short-medium term.

The authors have estimated the turnover that Venetian fishermen could potentially receive from fisheries-related tourism activities, and in particular from pesca-tourism. Since the process to support a concrete development of pesca-tourism has already begun whereas ichthytourism still requires some regulatory clarifications in order to put fishermen in the right conditions to exercise it, analyses focussed only on pesca-tourism and did not consider ichthytourism.

The authors have analysed three different scenarios, corresponding one to the short term (year 2016), another one to the medium term (year 2018) and the last one to the long-term (year 2020), in order to take into consideration the evolution of the supply and other conditions and consequently to verify how turnover can change.

The scenarios consider various variables, such as the number of fishermen who will start pesca-tourism activities, the number of weeks dedicated to this activity, the number of excursions per week, the excursion price and the maximum number of passengers acceptable on board.

The hypothesis for each of these variables and the turnover evaluation have been developed according to the following elements:

- the potential demand estimation;

- a survey among a sample of 50 Venetian fishermen who have been interviewed about the characteristics of their fishing activities, the willingness to start pesca-tourism and the conditions under which to practice this activity; 
- a focus group with the main stakeholders of the Venetian fisheries sector (the local FLAG, the regional body, representatives of fishermen's cooperative associations, etc.).

Three scenarios are below described and commented.

1. Short term (year 2016) - Since many fishermen among those who have attended the training course have not yet fulfilled all other obligations, the first scenario assumes that only 15 fishermen are able to develop and organise a well-structured supply of pesca-tourism excursions. Since they have to combine this activity with their main fishing practise and since excursions are influenced by weather conditions, the hypothesis it that they work 20 weeks in a year with 2 excursions per week ( 40 overall). The price of each trip is set at $€ 50.00$ per person, consistently with the costs both of similar experiences in other regions and of other competitive recreational activities in the area. The maximum number of non-crew passengers is 12 visitors according to national law. Under these hypothesis, every fisherman could benefit from a turnover of $€ 24,000$ per year. Furthermore, since the potential demand is estimated at 110,000 visitors, there would still be almost 100,000 people to satisfy; the demand is large enough to give other fishermen the possibility to enter the market.

2. Medium term (year 2018) - It is realistic that other fishermen, driven by the success of their colleagues' initiatives, decide to invest in pesca-tourism in the medium term, so that the number of fishermen increases from 15 to 36 . Furthermore it can be assumed that the know-how acquired over the years by fishermen ensures a better supply organisation, allowing operators to work 24 weeks per year with 2 excursions per week. The turnover could then amount to $€ 29,000$ per year per fisherman and the demand would still be large enough to satisfy all operators.

3. Long term (year 2020) - This last scenario assumes that 54 fishermen practice pescatourism for 30 weeks per year and 2 excursions per week. Each fisherman could benefit from a turnover of $€ 36,000$ yearly. There would still be almost 69,000 clients to cater for, allowing either other 54 fishermen to start the activity or the operators already operating in the market to propose even 4 excursions in a week.

Table 2: Fishermen turnover.

\begin{tabular}{llll}
\hline & $\begin{array}{c}\text { Short term } \\
\text { (year 2016) }\end{array}$ & $\begin{array}{c}\text { Medium term } \\
\text { (year 2018) }\end{array}$ & $\begin{array}{c}\text { Long term } \\
\text { (year 2020) }\end{array}$ \\
\hline $\begin{array}{l}\mathrm{N}^{\circ} \text { of fishermen offering pesca-tourism } \\
\text { excursions }\end{array}$ & 15 & 36 & 54 \\
$\mathrm{~N}^{\circ}$ of week per year & 20 & 24 & 30 \\
$\mathrm{~N}^{\circ}$ of excursions per week & 2 & 2 & 2 \\
Price of excursion & $€ 50.00$ & $€ 5000$ & $€ 5000$ \\
$\mathrm{~N}^{\circ}$ of passengers & 12 & 12 & 12 \\
Turnover per year per fishermen from & $€ \mathbf{2 4 , 0 0 0 . 0 0}$ & $€ \mathbf{2 9 , 0 0 0 . 0 0}$ & $€ \mathbf{3 6 , 0 0 0 . 0 0}$ \\
pesca-tourism & & & 39,000 \\
Demand satisfied by fishermen & 8,000 & 21,000 & 69,000 \\
Demand not satisfied yet & 100,000 & 87,000 & \\
\hline
\end{tabular}


The scenarios discussed above reveal not only the existence of a potential demand that is large enough to guarantee a satisfactory result for all operators but also the opportunity for every fisherman to benefit from an additional turnover of $€ 24,000-36,000$ per year. Even though a part of this turnover must cover the costs such as fuel and personnel, the interviewed fishermen and stakeholders agree that the amount coming from pesca-tourism can guarantee a significant source of income in addition to fishing turnover.

\subsection{Benefits for the destination deriving from visitors' expenditure}

After verifying that fisheries-related tourism can represent an interesting opportunity for Venetian fishermen in term of integration of their income, another matter is to understand whether it can bring positive impacts also in the destination. The analysis refers in particular to direct economic impacts, in other words, those directly produced by the expenditure of visitors who carry out fisheries-related tourism activities. The entity of these revenues is mainly linked to two factors, the level of development of fisheries-related tourism supply - in the short, medium and long term - and visitors' origin and spending.

It is important to consider that the potential demand of almost 110,000 visitors is made up of residents for the $87 \%$ and of tourists for the $13 \%$. It is realistic to suppose that in the short term the clients satisfied by pesca-tourism supply (8,000 visitors) are almost all residents (98\%), since it is easier for them to become aware of the existence of pesca-tourism excursions. However, in the long term, a gradual increase of the tourists' share, thanks to a stronger promotion of pesca-tourism and to a better organisation and commercialisation of the supply, is expercted; the tourists' share can reach about $10 \%$ of the demand satisfied in the long term (39,000 visitors).

In terms of visitors' expenditure, according to several studies carried out by the authors on tourists' and consumers' behaviour and consumption in the Veneto Region [13-16], we can differentiate residents' expenditure from tourists' expenditure, in particular by assuming the following:

- residents choosing pesca-tourism excursions spend an average of $€ 50.00$ per person, including excursion by boat and the lunch offered by the fisherman; since this activity takes half a day or a whole day, it is reasonable that residents do not consume other services unless for insignificant spending (an ice-cream, a bottle of water, etc);

Table 3: Economic benefits on the destination.

\begin{tabular}{|c|c|c|}
\hline & Short term (2016) & Long term (2020) \\
\hline Demand satisfied by fishermen & 8,000 & 39,000 \\
\hline Residents & $98 \%$ & $90 \%$ \\
\hline Tourists & $2 \%$ & $10 \%$ \\
\hline $\begin{array}{l}\text { Average daily residents' expenditure } \\
\text { per person }\end{array}$ & $€ 50.00$ & $€ 50.00$ \\
\hline $\begin{array}{l}\text { Average daily tourists' expenditure } \\
\text { per person for the additional night }\end{array}$ & 120.00 & $€ 120.00$ \\
\hline Total expenditure in the destination & $€ 360,000$ & $€ 2, \mathbf{2 0 0 , 0 0 0}$ \\
\hline
\end{tabular}


- tourists on holiday in Venetian seaside resorts or in neighbouring destinations can consider the pesca-tourism excursion as an opportunity to extend their stay for one more night in order to carry out this activity. The daily tourists' expenditure amounts on average to $€ 120.00$ per person. Since accommodation accounts for $35 \%$ of the total expenditure (€42.00) and the excursion's price (including lunch on board) is $€ 50.00$, the remaining $€ 30.00$ can be dedicated by tourists to other purchases such as guided visits, traditional products, visits to naturalistic, sea and maritime museums, etc.

Definitely, visitors' expenditure for fisheries-related tourism experiences and for other related activities can amount to $€ 360,000$ in the short term and then even increase to 2.2 millions in 2020. It is evident that returns on the destination are higher in the long term, when it can benefit from a likely increase in tourists' length of stay (an additional night) and then in their expenditure on-site.

\section{GUIDELINES}

The above mentioned economic opportunities can become concrete outcomes only under certain conditions. Fishermen, the tourism system and legislators all play a key role in realizing the following conditions.

First, fishermen should create and package their tourism offer year by year by clearly defining number and schedule of excursions and/or other activities per week, number of clients per activity and prices. Pricing definition should take into account clients's typology and spending power, market conditions, trade margins and input costs, competitors' actions. Competitors can be other fishermen in the same destination but also tourism operators selling generic boat excursions, trekking excursions along the coasts or in the lagoon, visits to rural areas and natural parks as well as amusement parks.

The definition of a well organised activity or set of activities is strategic so that fishermen are clearly recognized both by tourists and by tour operators and travel agencies willing to sell their tourism product.

Moreover fishermen should create a network among them not only to better respond to clients' demand when reservations increase and special requests are formulated but also in order to improve their bargaining power in negotiating with tour operators, to reach a higher visibility in the market, and to benefit of cost reduction for communication campaigns and promotion actions.

Secondly, the tourism system as a whole should plan strategies for the integration of different local resources and tourism services with fisheries-related tourism products. For example visits to local museums describing territorial uniqueness can be combined with boat excursions, or hotel owners can propose fishermen excursions to their clients. An integrated offer is strategic to formulate adequate packages by differentiating them according to specific segments i.e. families with kids, elderly people, fishing lovers, etc.

Thirdly, stakeholders such as the local FLAG, institutional actors, tourism consortia, play a key role in supporting and facilitating fishermen tourism business, coordinating promotional initiatives even among different sectors.

Finally, another important subject who can help fisheries-related tourism products succeed is the national and regional legislator, who should foster a normative simplification and the resolution of outstanding issues such as engine power, health and hygiene standard definition. 


\section{CONCLUSIONS}

The analysis confirms first of all that the high socio-economic potential of fisheries-related tourism demands for a better regulation, coordination and integration of the sector, at a regional, national and international level. The first step should be an internationally shared definition of fisheries-related tourism. Moreover, a more exhaustive and appropriate legislative framework for the development of fisheries-related tourism activities in the Mediterranean is thus required at different territorial levels.

Secondly, the study verifies that fisheries-related tourism can be economically sustainable under specific conditions requiring coordination among actors in the same destination. The fulfilment of these conditions is the first step to develop successful fisheries-related tourism not only in the Venetian coastal area but in all coastal destinations where fishermen proposals can potentially represent a niche product and a way of differentiating tourism supply. The proposed methodological approach can be extended worldwide in any fisheries-related tourism experience where a sort of economic feasibility study is required.

Further economic analyses should foresee an accurate monitoring of outcomes, i.e. the effective fulfilment of the above mentioned conditions as well the actual fishermen turnover in a short, medium and long term, and real benefits for the destination. Monitored impacts should include not only economic return but also other impacts such as the ability of fisheries-related tourism to attract customers off season or to divert groups from overcrowded to less known areas.

Moreover, monitoring impacts means guaranteeing step by step that fisheries-related tourism activities are really compatible with a sustainable development in terms of environmental preservation of sensitive areas.

Finally, social impacts deriving from fisheries-related tourism activities should also be evaluated, such as the increase in the number of people, particularly young people, working in the sector, the capacity to favour effective business transfer and the promotion of economic sectors safeguarding artisanal activities and local productions risking disappearance.

\section{REFERENCES}

[1] Malorgio, M., Mulazzani, L., Di Terlizzi, B., Zuccaro, M. \& Petruzzella, D., Enhancing Small-Scale Fisheries Value Chains in the Mediterranean and Black Sea, 2015, available at http://www.ssfsymposium.org/Documents/FullVersion/BPIV_Part2.pdf

[2] Farnet, Fisheries and Tourism. Creating benefits for the community, European Commission, 2014.

[3] Mulazzani, L., Trevisi, R., Manrique, R. \& Malorgio, G., Community-led Coastal Development and the Relationships between Human Activities and Ecosystem Services, available at http://www.eafe2015.unisa.it/papers/comunitycostal.

[4] Adhelhamid, S.B., Etude de faisabilité pour le développement de la pêche tourisme dans les régions du Golfe de Gabes Tunisie, Institut National Agronomique de Tunisie, 2014.

[5] Farnet Magazine, Linking Fisheries to the Tourism Economy, European Commission, $\mathrm{N}^{\circ} 9$ autumn-winter, 2013.

[6] Farnet, Project Case Study. Pescatourisme83, European Commission, 2011.

[7] Farmet, Project Summary. Mar Galaica, European Commission, 2014.

[8] Farnet, Project Summary. Tourism Training for Fishermen, European Commission, 2012. 
[9] Council Regulation EC N. 1198/2006 on the European Fisheries Fund, Chapter IV, Articles 43-45, 2006.

[10] Italian National Legislative Decree D.Lgs. n. 154/2004. Modernisation of the fisheries and aquaculture sector, art. 7.

[11] Farnet, Report - Linking fisheries to the tourism economy, 9th Transnational Seminar for Fisheries Local Action Groups, Sardinia, Italy, 22-24 October 2013.

[12] CISET, VeGAL-VeGAC, Guide lines for pesca-ichthytourism along Venetian coasts, 2014, Unpublished report.

[13] CISET, study commissioned by Association of Caorle and Bibione Lagoon, Analysis of tourists' sensitivity to the proposal of a Natural Park in the Eastern Veneto, 2004, Unpublished report.

[14] CISET, study commissioned by Comune di Quarto d'Altino, Feasibility Study for the "Altinate" Area Development, 2010, Unpublished report.

[15] CISET, study commissioned by Regione Veneto, Analysis of the German, Austrian and English Market in Veneto Region, 2010, Unpublished report.

[16] CISET, study commissioned by Provincia di Venezia, Strategic Plan for Tourism Development in the Province of Venezia, 2008-2010, Unpublished report. 